Review

\title{
Untargeted NMR-Based Methodology in the Study of Fruit Metabolites
}

\author{
Anatoly Petrovich Sobolev ${ }^{1}$, Luisa Mannina ${ }^{1,2, *}$, Noemi Proietti ${ }^{1}$, Simone Carradori ${ }^{3}$, \\ Maria Daglia ${ }^{4}$, Anna Maria Giusti ${ }^{5}$, Riccarda Antiochia ${ }^{2}$ and Donatella Capitani ${ }^{1}$
}

1 Magnetic Resonance Laboratory “Annalaura Segre”, Institute of Chemical Methodologies, National Research Council (CNR), I-00015 Monterotondo (RM), Italy;

E-Mails: anatoly.sobolev@cnr.it (A.P.S.); noemi.proietti@cnr.it (N.P.); donatella.capitani@cnr.it (D.C.)

2 Department of Drug Chemistry and Technologies, Sapienza University of Rome, Piazzale Aldo Moro 5, I-00185 Rome, Italy; E-Mail: riccarda.antiochia@uniroma1.it

3 Department of Pharmacy, “G. D’Annunzio” University of Chieti-Pescara, Via dei Vestini 31, 66100 Chieti Scalo (CH), Italy; E-Mail: simone.carradori@unich.it

4 Department of Drug Sciences, Medicinal Chemistry and Pharmaceutical Technology Section, Pavia University, Via Taramelli 12, 27100 Pavia, Italy; E-Mail: maria.daglia@unipv.it

5 Department of Experimental Medicine, Sapienza University of Rome, Piazzale Aldo Moro 5, I-00185 Rome, Italy; E-Mail: annamaria.giusti@uniroma1.it

* Author to whom correspondence should be addressed; E-Mail: luisa.mannina@uniroma1.it; Tel.: +39-06-4991-3735; Fax: +39-06-9067-2477.

Academic Editor: Derek J. McPhee

Received: 23 December 2014 / Accepted: 26 February 2015 / Published: 4 March 2015

\begin{abstract}
In this review, fundamental aspects of the untargeted NMR-based methodology applied to fruit characterization are described. The strategy to perform the structure elucidation of fruit metabolites is discussed with some examples of spectral assignments by 2D experiments. Primary ubiquitous metabolites as well as secondary species-specific metabolites, identified in different fruits using an untargeted ${ }^{1} \mathrm{H}-\mathrm{NMR}$ approach, are summarized in a comprehensive way. Crucial aspects regarding the quantitative elaboration of spectral data are also discussed. The usefulness of the NMR-based metabolic profiling was highlighted using some results regarding quality, adulteration, varieties and geographical origin of fruits and fruit-derived products such as juices.
\end{abstract}


Keywords: NMR; fruits; metabolomics; primary metabolites; secondary metabolites

\section{Introduction}

All fruits have a specific chemical profile mostly characterized by endogenous components (produced by the plant and by environmental microorganisms) that are strongly connected to their nutritional value, aroma, taste and health-promoting effects. These fruit components can be ubiquitous primary metabolites (such as amino acids, sugars, organic acids) involved in the basic functions of the living cells or secondary metabolites that are usually fruit-type specific. Taken together these metabolites can be used as potential markers for quality, origin and authenticity of fruit and fruit-derived foods.

Taking into account the great variety of fruit-derived foodstuffs, numerous chemical and physico-chemical methods of analysis have been proposed to control their sensorial and nutritional properties, quality and authenticity [1]. Analytical methodologies, called targeted analyses, focus on a specific class of compounds or single compounds significant for assessing foodstuff quality, nutritional/sensorial properties, and biological characteristics. In the case of targeted analyses, selective extractions and/or separations are usually performed before the analysis to isolate and concentrate the selected metabolites and to avoid interference from other compounds. The targeted approach provides reliable and sensitive identification and precise and accurate quantification of specific compounds. In literature, many analytical methodologies such as chromatography, spectrophotometry, and spectroscopic techniques have been applied to determine specific fruits metabolites. Typical fruit target compounds are phenolics, sugars, amino acids and organic acids.

Other analytical methodologies, called untargeted analyses, are not focused on specific target compounds and try to give a picture as complete as possible of the chemical composition of the investigated sample. In the case of untargeted analyses, metabolite extraction from fruits is carried out choosing the solvent or the mixture of solvent able to extract the highest number of metabolites.

Metabolomics, as a non-biased identification and quantification of all metabolites present in a given matrix, uses untargeted analytical methodologies [2]. In metabolomics a wide range of different compounds with different chemical natures, solubility and concentration has to be analyzed. Generally, fruit metabolomics is extremely complex due to the enormous diversity of metabolite chemical structures present in plants, especially among the secondary metabolites which are specific for every species. In the last few years, metabolomic studies have experienced a notable increase in interest, producing many important results from an analytical point of view [3]. Among the untargeted analytical methodologies used to analyze fruits, NMR-based metabolomics has gained an important role because it can simultaneously bring "high-throughput" spectroscopic/structural information on a wide range of metabolites with a high analytical precision [4] avoiding biases against certain classes of compounds. The ${ }^{1} \mathrm{H}-\mathrm{NMR}$ spectra of fruits extracts are inevitably crowded because of the presence of many compounds. However, NMR is also especially helpful for the identification of secondary metabolites in fruit extracts by means of 1D and 2D experiments, standard additions and by comparison with literature databases. 
In this review, some important aspects (spectral assignments, quantitative analysis and statistical elaboration) of the use of NMR methodology for fruit extract characterization are reported together with an overview of the current literature data regarding the metabolites identified by the untargeted NMR approach. The usefulness of the metabolite profiling in variety discrimination and in the investigation of fruit development and ripening, quality and geographical origin is evidenced.

\section{Metabolic Profile: Spectral Assignment, Quantitative Analysis and Statistical Elaboration}

\subsection{Spectral Assignment}

Fruit composition is extremely complex due to the enormous diversity of metabolite chemical structures present in fruits, especially regarding the secondary metabolites specific for each botanical species. As a consequence, highly crowded ${ }^{1} \mathrm{H}-\mathrm{NMR}$ spectra of fruit extracts are usually obtained owing to the presence of hundreds of multiplet resonances. In order to simplify the spectra and to disentangle overlapped signals, the spectral assignment strategies inevitably include two-dimensional NMR experiments such as homonuclear correlations like ${ }^{1} \mathrm{H}-{ }^{1} \mathrm{H}$ COSY and/or ${ }^{1} \mathrm{H}-{ }^{1} \mathrm{H}$ TOCSY, or heteronuclear correlations like ${ }^{1} \mathrm{H}-{ }^{13} \mathrm{C} \mathrm{HSQC}$ and ${ }^{1} \mathrm{H}-{ }^{13} \mathrm{C}$ HMBC [5]. Among homonuclear correlation experiments, ${ }^{1} \mathrm{H}-{ }^{1} \mathrm{H}$ TOCSY is particularly feasible for mixture analysis allowing the assignment of all hydrogen signals within a spin system that forms an unbroken chain of couplings, thereby entire molecules or molecular fragments can be assigned, see Figure 1.
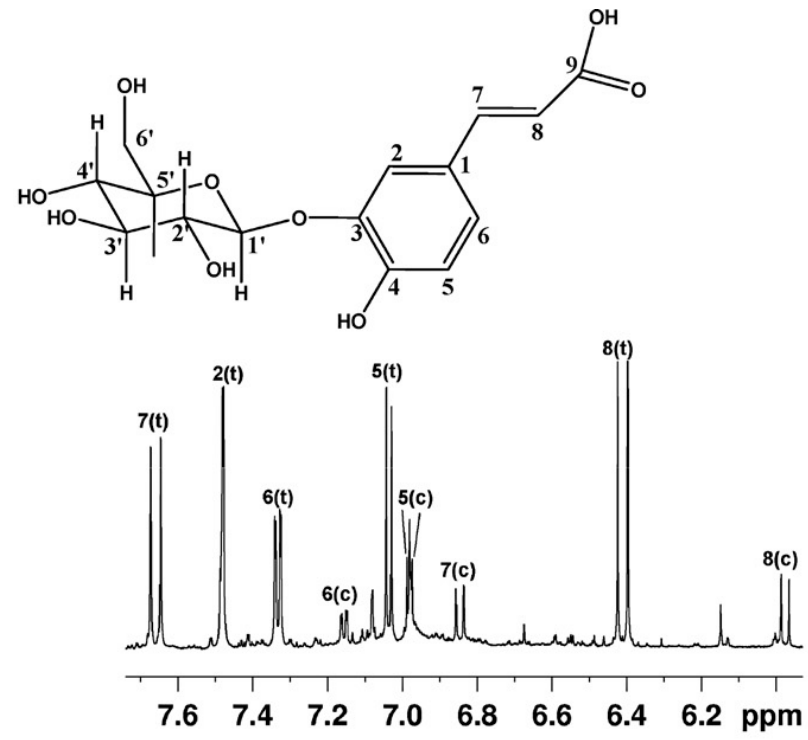

(A)

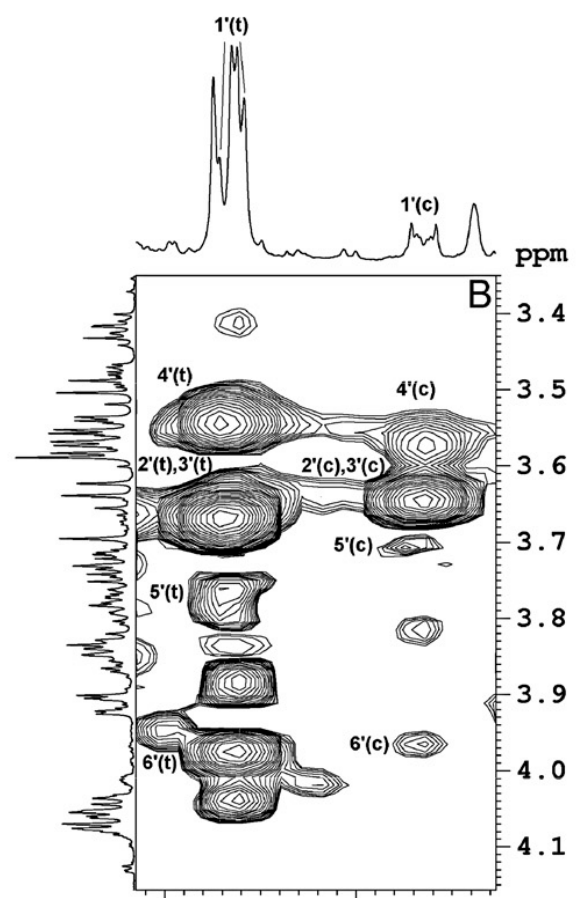

(B)

Figure 1. (A) ${ }^{1} \mathrm{H}$ expanded spectral region and assignment of aromatic and vinyl protons of $\mathrm{O}^{3}$ - $\beta$-glucopyranosyl-trans-caffeic acid and $\mathrm{O}^{3}$ - $\beta$-glucopyranosyl-cis-caffeic acid $(\mathrm{c}=$ cis; $\mathrm{t}=$ trans $)$. (B) Expansion of ${ }^{1} \mathrm{H}-{ }^{1} \mathrm{H}$ TOCSY map, the proton spin system of the glucopyranosyl moiety of $\mathrm{O}^{3}-\beta$-glucopyranosylcaffeic acid is shown (reproduced with permission from [6]). 
Heteronuclear ${ }^{1} \mathrm{H}_{-}{ }^{13} \mathrm{C}$ correlation experiments have the advantage of spreading the metabolite signals in the ${ }^{13} \mathrm{C}$ dimension over a broader range $(0-200 \mathrm{ppm})$ respect to that of ${ }^{1} \mathrm{H}$ dimension $(0-10 \mathrm{ppm})$ and to observe indirectly ${ }^{13} \mathrm{C}$ spectrum with higher sensitivity through the use of inverse detection. Apart from various 2D-experiments, diffusion ordered NMR spectroscopy (DOSY) [7] offers an additional support for the structure elucidation of complex mixtures giving information regarding the self-diffusion coefficients of the metabolites present in the sample. DOSY is a particularly convenient way of displaying the molecular self-diffusion information in a bidimensional array, with the NMR spectrum in one dimension and the self-diffusion coefficient in the other one. Therefore, different components in a fruit extract can be distinguished by their self-diffusion coefficients as reported for fruit juices by Gil et al. [8]. The detailed description of NMR spectral assignment methods applied to complex mixtures can be found elsewhere [9,10].

Using the NMR approach it has been possible to identify primary as well as secondary metabolites of different fruits such as grape, orange, apple juice, mandarin orange, kiwifruits, mango, black raspberry, melon, watermelon, blueberry and peaches, see Table 1 . The presence of a metabolite in a given foodstuff is indicated by the letter X. In this type of NMR based analyses, the extraction procedure is probably the most critical step aimed to the quantitative transfer of the metabolites from the solid matrix into the solution. Note that the major part of metabolites has been extracted and identified in aqueous solutions. In the case of phenolic compounds poorly soluble in water, the mixture of water and methanol is usually used for extraction and subsequent NMR analysis. In some specific cases, in order to obtain high resolution NMR spectra, methanol with trifluoroacetic acid has been used for fruit extraction and then deuterated methanol as NMR solvent [11].

Each fruit shows a characteristic set of primary ubiquitous metabolites (such as amino acids, sugars, and organic acids) involved in the basic functions of living cells. Anyway, the amount of primary metabolites varies in different fruits. These differences can be directly observed in ${ }^{1} \mathrm{H}-\mathrm{NMR}$ spectra (see as an example Figure 2, in which the ${ }^{1} \mathrm{H}-\mathrm{NMR}$ spectra of kiwifruits, blueberries and peaches are compared).

Usually for the assignment of a specific metabolite in the complex spectra of fruit extracts at least one signal of this metabolite has to be resolved from other signals in the spectrum. Unfortunately, not all metabolites have this "diagnostic" signal. For example, pyruvate has only one signal from its $\mathrm{CH}_{3}$ group in the range $2.35-2.40 \mathrm{ppm}$ that usually is overlapped with the multiplet signals of other almost ubiquitous metabolites such as glutamate and glutamine. As a consequence, only a relatively high concentration of pyruvate is detectable, therefore its detection limit in mixture is substantially higher than that for a single compound. On the other hand, the metabolites with characteristic signals not overlapped with other components are well detectable also when they are present in low concentration as for example Val, Leu, Ile and Ala (see Figure 3). 
Table 1. Metabolites identified in ${ }^{1} \mathrm{H}-\mathrm{NMR}$ spectra of fruit extracts.

\begin{tabular}{|c|c|c|c|c|c|c|c|c|c|c|c|}
\hline Metabolite & Grape $^{\text {a }}$ & $\begin{array}{l}\text { Orange } \\
\text { Juice }^{\text {b }}\end{array}$ & $\begin{array}{l}\text { Apple } \\
\text { Juice }^{\text {c }}\end{array}$ & $\begin{array}{l}\text { Mandarin } \\
\text { Orange }^{d} \\
\end{array}$ & Kiwifruit $^{e}$ & Mango $^{f}$ & $\begin{array}{l}\text { Black } \\
\text { Raspberry }\end{array}$ & Melon ${ }^{\mathrm{h}}$ & Watermelon $^{\mathrm{i}}$ & Blueberry $^{\mathbf{j}}$ & Peach $^{k}$ \\
\hline \multicolumn{12}{|l|}{ Acids } \\
\hline Acetic & $\mathbf{X}$ & & $\mathbf{X}$ & & & & $\mathbf{X}$ & $\mathbf{X}$ & & & \\
\hline Ascorbic & $\mathbf{X}$ & & & $\mathbf{X}$ & $\mathbf{X}$ & & $\mathbf{X}$ & & & & \\
\hline Citramalic & & & $\mathbf{X}$ & & & & & & & & \\
\hline Citric & $\mathbf{X}$ & $\mathbf{X}$ & $\mathbf{X}$ & $\mathbf{X}$ & $\mathbf{X}$ & $\mathbf{X}$ & $\mathbf{X}$ & $\mathbf{X}$ & $\mathbf{X}$ & $\mathbf{X}$ & $\mathbf{X}$ \\
\hline 3,4-Dihydroxybenzoic & & & & & & & $\mathbf{X}$ & & & & \\
\hline Formic & $\mathbf{X}$ & & $\mathbf{X}$ & $\mathbf{X}$ & & $\mathbf{X}$ & & & & & \\
\hline Fumaric & $\mathbf{X}$ & & & & & $\mathbf{X}$ & $\mathbf{X}$ & $\mathbf{X}$ & $\mathbf{X}$ & & $\mathbf{X}$ \\
\hline Glutaric & & & & & & & $\mathbf{X}$ & & & & \\
\hline 3-Hydroxybutyric & & & & & & $\mathbf{X}$ & $\mathbf{X}$ & & & & \\
\hline Lactic & $\mathbf{X}$ & & $\mathbf{X}$ & & $\mathbf{X}$ & $\mathbf{X}$ & $\mathbf{X}$ & & & & \\
\hline Maleic & & & & & & & $\mathbf{X}$ & & & & \\
\hline Malic & $\mathbf{X}$ & $\mathbf{X}$ & $\mathbf{X}$ & & $\mathbf{X}$ & $\mathbf{X}$ & & $\mathbf{X}$ & $\mathbf{X}$ & $\mathbf{X}$ & $\mathbf{X}$ \\
\hline Methyl-malonic & & & & & & $\mathbf{X}$ & & & & & \\
\hline Pyruvic & & & & & & & $\mathbf{X}$ & & & & \\
\hline Quinic & & $\mathbf{X}$ & $\mathbf{X}$ & & $\mathbf{X}$ & $\mathbf{X}$ & & & & $\mathbf{X}$ & $\mathbf{X}$ \\
\hline Shikimic & & & & & $\mathbf{X}$ & $\mathbf{X}$ & & & & $\mathbf{X}$ & $\mathbf{X}$ \\
\hline Succinic & $\mathbf{X}$ & $\mathbf{X}$ & $\mathbf{X}$ & $\mathbf{X}$ & & $\mathbf{X}$ & $\mathbf{X}$ & & & & $\mathbf{X}$ \\
\hline Tartaric & $\mathbf{X}$ & & $\mathbf{X}$ & & & $\mathbf{X}$ & & & & & \\
\hline \multicolumn{12}{|c|}{ Sugars and sugar alcohols } \\
\hline$\beta$-Arabinose & & & & & & $\mathbf{X}$ & & & & & \\
\hline$\alpha$-D-Fructofuranose & $\mathbf{X}$ & & $\mathbf{X}$ & $\mathbf{X}$ & $\mathbf{X}$ & $\mathbf{X}$ & $\mathbf{X}$ & $\mathbf{X}$ & $\mathbf{X}$ & $\mathbf{X}$ & $\mathbf{X}$ \\
\hline$\beta$-D-Fructofuranose & & $\mathbf{X}$ & & & $\mathbf{X}$ & & & & & $\mathbf{X}$ & $\mathbf{X}$ \\
\hline$\beta$-D-Fructopyranose & & & & & $\mathbf{X}$ & & & & & $\mathbf{X}$ & $\mathbf{X}$ \\
\hline Fructose-6P & & & & & $\mathbf{X}$ & & & & & & $\mathbf{X}$ \\
\hline Fucose & & & & & & $\mathbf{X}$ & & & & & $\mathbf{X}$ \\
\hline$\alpha$-Galactose & & & $\mathbf{X}$ & & $\mathbf{X}$ & & & $\mathbf{X}$ & & & \\
\hline$\beta$-Galactose & & & $\mathbf{X}$ & & $\mathbf{X}$ & $\mathbf{X}$ & & & & & \\
\hline$\alpha$-Glucose & $\mathbf{X}$ & $\mathbf{X}$ & $\mathbf{X}$ & $\mathbf{X}$ & $\mathbf{X}$ & $\mathbf{X}$ & $\mathbf{X}$ & $\mathbf{X}$ & $\mathbf{X}$ & $\mathbf{X}$ & $\mathbf{X}$ \\
\hline
\end{tabular}


Table 1. Cont.

\begin{tabular}{|c|c|c|c|c|c|c|c|c|c|c|c|}
\hline Metabolite & Grape $^{\text {a }}$ & $\begin{array}{l}\text { Orange } \\
\text { Juice }^{\text {b }}\end{array}$ & $\begin{array}{l}\text { Apple } \\
\text { Juice }^{\text {c }}\end{array}$ & $\begin{array}{l}\text { Mandarin } \\
\text { Orange }^{d} \\
\end{array}$ & Kiwifruit $^{e}$ & Mango $^{f}$ & $\begin{array}{l}\text { Black } \\
\text { Raspberry }\end{array}$ & Melon ${ }^{\text {h }}$ & Watermelon $^{\mathrm{i}}$ & Blueberry $^{\mathbf{j}}$ & Peach $^{k}$ \\
\hline \multicolumn{12}{|c|}{ Sugars and sugar alcohols } \\
\hline$\beta$-Glucose & $\mathbf{X}$ & $\mathbf{X}$ & $\mathbf{X}$ & $\mathbf{X}$ & $\mathbf{X}$ & $\mathbf{X}$ & $\mathbf{X}$ & $\mathbf{X}$ & $\mathbf{X}$ & $\mathbf{X}$ & $\mathbf{X}$ \\
\hline$\alpha$-Glucose-6P & & & & & $\mathbf{X}$ & & & & & & $\mathbf{X}$ \\
\hline$\beta$-Glucose-6P & & & & & $\mathbf{X}$ & & & & & & $\mathbf{X}$ \\
\hline Limonin glucoside & & & & $\mathbf{X}$ & & & & & & & \\
\hline$\alpha$-Mannose & & & & & $\mathbf{X}$ & & & & & & \\
\hline$\beta$-Mannose & & & & & $\mathbf{X}$ & & & & & & \\
\hline Myo-inositol & & & & $\mathbf{X}$ & $\mathbf{X}$ & & & $\mathbf{X}$ & & $\mathbf{X}$ & $\mathbf{X}$ \\
\hline Raffinose & & & & & $\mathbf{X}$ & & & & & & \\
\hline$\alpha$-Rhamnose & & & & & & & & & & & $\mathbf{X}$ \\
\hline$\beta$-Rhamnose & & & & & & $\mathbf{X}$ & & & & & $\mathbf{X}$ \\
\hline Stachyose & & & & & & & & $\mathbf{X}$ & & & \\
\hline Sucrose & $\mathbf{X}$ & $\mathbf{X}$ & $\mathbf{X}$ & $\mathbf{X}$ & $\mathbf{X}$ & $\mathbf{X}$ & $\mathbf{X}$ & $\mathbf{X}$ & $\mathbf{X}$ & $\mathbf{X}$ & $\mathbf{X}$ \\
\hline d-Trehalose & & & & & & & & $\mathbf{X}$ & & & \\
\hline$\alpha$-Xylose & & & $\mathbf{X}$ & & $\mathbf{X}$ & & & & & & $\mathbf{X}$ \\
\hline$\beta$-Xylose & & & $\mathbf{X}$ & & $\mathbf{X}$ & & & & & & $\mathbf{X}$ \\
\hline \multicolumn{12}{|c|}{ Amino acids, peptides and derivatives } \\
\hline Alanine & $\mathbf{X}$ & $\mathbf{X}$ & $\mathbf{X}$ & $\mathbf{X}$ & $\mathbf{X}$ & $\mathbf{X}$ & $\mathbf{X}$ & $\mathbf{X}$ & & $\mathbf{X}$ & $\mathbf{X}$ \\
\hline$\gamma$-Amino-butyrate & $\mathbf{X}$ & $\mathbf{X}$ & $\mathbf{X}$ & $\mathbf{X}$ & $\mathbf{X}$ & $\mathbf{X}$ & & $\mathbf{X}$ & $\mathbf{X}$ & $\mathbf{X}$ & \\
\hline Arginine & $\mathbf{X}$ & $\mathbf{X}$ & & $\mathbf{X}$ & $\mathbf{X}$ & $\mathbf{X}$ & $\mathbf{X}$ & & & $\mathbf{X}$ & \\
\hline Asparagine & & $\mathbf{X}$ & $\mathbf{X}$ & $\mathbf{X}$ & $\mathbf{X}$ & $\mathbf{X}$ & $\mathbf{X}$ & $\mathbf{X}$ & & $\mathbf{X}$ & $\mathbf{X}$ \\
\hline Aspartate & & $\mathbf{X}$ & $\mathbf{X}$ & $\mathbf{X}$ & $\mathbf{X}$ & $\mathbf{X}$ & $\mathbf{X}$ & $\mathbf{X}$ & & & \\
\hline Citrulline & & & & & & & $\mathbf{X}$ & & $\mathbf{X}$ & & \\
\hline Dimethyl-proline & & $\mathbf{X}$ & & & & & & & & & \\
\hline Glutamate & $\mathbf{X}$ & $\mathbf{X}$ & $\mathbf{X}$ & & $\mathbf{X}$ & $\mathbf{X}$ & $\mathbf{X}$ & $\mathbf{X}$ & & $\mathbf{X}$ & \\
\hline Glutamine & $\mathbf{X}$ & $\mathbf{X}$ & & & $\mathbf{X}$ & $\mathbf{X}$ & $\mathbf{X}$ & $\mathbf{X}$ & $\mathbf{X}$ & $\mathbf{X}$ & \\
\hline Glycine & & & & & & & $\mathbf{X}$ & & & & \\
\hline Histidine & & $\mathbf{X}$ & & $\mathbf{X}$ & $\mathbf{X}$ & & & & & & \\
\hline Isoleucine & $\mathbf{X}$ & & $\mathbf{X}$ & $\mathbf{X}$ & $\mathbf{X}$ & $\mathbf{X}$ & $\mathbf{X}$ & $\mathbf{X}$ & $\mathbf{X}$ & & $\mathbf{X}$ \\
\hline
\end{tabular}


Table 1. Cont.

\begin{tabular}{|c|c|c|c|c|c|c|c|c|c|c|c|}
\hline Metabolite & Grape $^{a}$ & $\begin{array}{l}\text { Orange } \\
\text { Juice }{ }^{b}\end{array}$ & $\begin{array}{l}\text { Apple } \\
\text { Juice }^{c}\end{array}$ & $\begin{array}{l}\text { Mandarin } \\
\text { Orange d }\end{array}$ & Kiwifruit $^{\mathrm{e}}$ & Mango ${ }^{f}$ & $\begin{array}{l}\text { Black } \\
\text { Raspberry } \mathrm{g}\end{array}$ & Melon ${ }^{\mathrm{h}}$ & Watermelon ${ }^{\mathrm{i}}$ & Blueberry ${ }^{j}$ & Peach k \\
\hline \multicolumn{12}{|l|}{ Amino acids, peptides and derivatives } \\
\hline Leucine & $\mathbf{X}$ & & $\mathbf{X}$ & $\mathbf{X}$ & $\mathbf{X}$ & $\mathbf{X}$ & $\mathbf{X}$ & & & $\mathbf{X}$ & \\
\hline Lysine & & & & & $\mathbf{X}$ & $\mathbf{X}$ & & & & & \\
\hline Methionine & $\mathbf{x}$ & & & & & & & & & & \\
\hline Ornithine & & $\mathbf{X}$ & & & & $\mathbf{X}$ & & & & & \\
\hline Phenylalanine & & $\mathbf{X}$ & & $\mathbf{X}$ & $\mathbf{x}$ & $\mathbf{X}$ & $\mathbf{x}$ & $\mathbf{X}$ & & & $\mathbf{X}$ \\
\hline Proline & $\mathbf{X}$ & $\mathbf{X}$ & & $\mathbf{X}$ & & & $\mathbf{X}$ & & & & \\
\hline Proline-betaine & & & & $\mathbf{x}$ & & & & & & & \\
\hline Pyroglutamate & & & & & & & & $\mathbf{X}$ & & & \\
\hline Threonine & $\mathbf{X}$ & $\mathbf{X}$ & & $\mathbf{X}$ & $\mathbf{X}$ & $\mathbf{X}$ & & $\mathbf{X}$ & & $\mathbf{X}$ & $\mathbf{X}$ \\
\hline Tryptophane & & & & & $\mathbf{X}$ & & & $\mathbf{X}$ & & & \\
\hline Tyrosine & & $\mathbf{X}$ & & & & & $\mathbf{X}$ & $\mathbf{X}$ & & & \\
\hline Valine & $\mathbf{x}$ & $\mathbf{X}$ & $\mathbf{X}$ & $\mathbf{x}$ & $\mathbf{X}$ & $\mathbf{X}$ & $\mathbf{x}$ & $\mathbf{X}$ & $\mathbf{X}$ & $\mathbf{X}$ & $\mathbf{X}$ \\
\hline \multicolumn{12}{|l|}{$\begin{array}{l}\text { Alcohols, polyols, amines, aldehydes, } \\
\text { ketones, esters }\end{array}$} \\
\hline Acetaldehyde hydrate & & & & & & $\mathbf{X}$ & & & & & \\
\hline $\begin{array}{l}\text { Benzoic acid } \beta \text {-D-glucopyranosyl } \\
\text { ester }\end{array}$ & & & & & & & $\mathbf{x}$ & & & & \\
\hline 2,3-Butanediol & $\mathbf{x}$ & & & & & & & & & & \\
\hline Choline & $\mathbf{x}$ & & & $\mathbf{X}$ & $\mathbf{X}$ & $\mathbf{X}$ & & $\mathbf{X}$ & & $\mathbf{X}$ & $\mathbf{X}$ \\
\hline Ethanol & & $\mathbf{X}$ & $\mathbf{X}$ & $\mathbf{X}$ & & $\mathbf{X}$ & & $\mathbf{X}$ & & & \\
\hline Galactinol & & & & & & & & $\mathbf{X}$ & & & \\
\hline a-Glycerophosphoryl choline & & & & & & & & & & & $\mathbf{X}$ \\
\hline Histamine & & & & & & & $\mathbf{X}$ & & & & \\
\hline Methanol & & & & $\mathbf{X}$ & & $\mathbf{X}$ & & & & & \\
\hline Methyl-amine & & & & & & $\mathbf{x}$ & & & & & \\
\hline Propanol & & & $\mathbf{X}$ & & & & & & & & \\
\hline L-Rhamnitol & & & $\mathbf{X}$ & & & & & & & & \\
\hline Salicylic acid $\beta$-D-glucopyranosyl ester & & & & & & & $\mathbf{X}$ & & & & \\
\hline
\end{tabular}


Table 1. Cont.

\begin{tabular}{|c|c|c|c|c|c|c|c|c|c|c|c|}
\hline Metabolite & Grape $^{a}$ & $\begin{array}{l}\text { Orange } \\
\text { Juice }^{\text {b }}\end{array}$ & $\begin{array}{l}\text { Apple } \\
\text { Juice }^{\text {c }}\end{array}$ & $\begin{array}{l}\text { Mandarin } \\
\text { Orange }\end{array}$ & Kiwifruit $^{\mathrm{e}}$ & Mango $^{f}$ & $\begin{array}{l}\text { Black } \\
\text { Raspberry } g\end{array}$ & Melon ${ }^{\text {h }}$ & Watermelon ${ }^{\mathrm{i}}$ & Blueberry $^{j}$ & Peach $^{k}$ \\
\hline \multicolumn{12}{|l|}{ Nucleic acid derivatives } \\
\hline Adenine & & & & & & $\mathbf{X}$ & & & & & \\
\hline Adenosine & & & & $\mathbf{X}$ & & & & & & & \\
\hline Adenosine-MP & & & & & & & & $\mathbf{X}$ & & & \\
\hline ATP & & & & & $\mathbf{X}$ & & & & & & $\mathbf{X}$ \\
\hline Uridine & & & & & $\mathbf{X}$ & & & & & & $\mathbf{X}$ \\
\hline \multicolumn{12}{|l|}{ Aromatic Compounds } \\
\hline Caffeic acid & & & & & & & $\mathbf{X}$ & & & & \\
\hline cis-Caftaric acid & $\mathbf{x}$ & & & & & & & & & & \\
\hline trans-Caftaric acid & $\mathbf{x}$ & & & & & & & & & & \\
\hline$(+)$-Catechin & $\mathbf{x}$ & & & & & & & & & & $\mathbf{X}$ \\
\hline Chlorogenic acid & & & $\mathbf{X}$ & & & & & & & $\mathbf{X}$ & $\mathbf{X}$ \\
\hline Cinnamic acid & & & & & & & $\mathbf{x}$ & & & & \\
\hline$p$-Coumaric acid & & & $\mathbf{x}$ & & & & $\mathbf{x}$ & & & & \\
\hline$p$-Coumaryl glucoside & & & & & & & $\mathbf{x}$ & & & & \\
\hline cis-p-Coutaric acid & $\mathbf{X}$ & & & & & & & & & & \\
\hline trans-p-Coutaric acid & $\mathbf{X}$ & & & & & & & & & & \\
\hline Cyanidin-3-glucoside & & & & & & & $\mathbf{X}$ & & & & \\
\hline Cyanidin-3-rutinoside & & & & & & & $\mathbf{X}$ & & & & \\
\hline Cyanidin-3-sambubioside & & & & & & & $\mathbf{x}$ & & & & \\
\hline Cyanidin-3-xylosylrutinoside & & & & & & & $\mathbf{x}$ & & & & \\
\hline Delphinidin-3-galactoside & & & & & & & & & & $\mathbf{X}$ & \\
\hline Delphinidin-3-glucoside & & & & & & & & & & $\mathbf{x}$ & \\
\hline Dihydrokaempferol glucoside & & & & & & & $\mathbf{x}$ & & & & \\
\hline Dihydrosinapic acid & & & & & & & $\mathbf{x}$ & & & & \\
\hline Ellagic acid & & & & & & & $\mathbf{x}$ & & & & \\
\hline (-)-Epicatechin & $\mathbf{x}$ & & $\mathbf{x}$ & & $\mathbf{X}$ & & $\mathbf{x}$ & & & & \\
\hline trans-Fertaric acid & $\mathbf{X}$ & & & & & & & & & & \\
\hline Ferulic acid & & & & & & & $\mathbf{X}$ & & & & \\
\hline Gallic acid & $\mathbf{X}$ & & & & & $\mathbf{X}$ & $\mathbf{X}$ & & & & \\
\hline
\end{tabular}


Table 1. Cont.

\begin{tabular}{|c|c|c|c|c|c|c|c|c|c|c|c|}
\hline Metabolite & Grape $^{a}$ & $\begin{array}{l}\text { Orange } \\
\text { Juice }^{\text {b }}\end{array}$ & $\begin{array}{l}\text { Apple } \\
\text { Juice }^{\text {c }}\end{array}$ & $\begin{array}{l}\text { Mandarin } \\
\text { Orange d }\end{array}$ & Kiwifruit ${ }^{\mathrm{e}}$ & Mango $^{f}$ & $\begin{array}{l}\text { Black } \\
\text { Raspberry }\end{array}$ & Melon $^{\mathrm{h}}$ & Watermelon $^{\mathrm{i}}$ & Blueberry ${ }^{j}$ & Peach $^{k}$ \\
\hline \multicolumn{12}{|l|}{ Aromatic Compounds } \\
\hline GLUcCA & & & & & $\mathbf{X}$ & & & & & & \\
\hline GLUtCA & & & & & $\mathbf{X}$ & & & & & & \\
\hline Malvidin-3-galactoside & & & & & & & & & & $\mathbf{X}$ & \\
\hline Malvidin-3-glucoside & & & & & & & & & & $\mathbf{X}$ & \\
\hline Methyl ellagic acid acetylpentose & & & & & & & $\mathbf{X}$ & & & & \\
\hline Myricetin & $\mathbf{X}$ & & & & & & & & & & \\
\hline Myricetin glucoside & & & & & & & $\mathbf{X}$ & & & & \\
\hline Narirutin & & $\mathbf{X}$ & & & & & & & & & \\
\hline Neochlorogenic acid & & & & & $\mathbf{X}$ & & & & & & $\mathbf{X}$ \\
\hline Niacin & & & & & & $\mathbf{X}$ & & & & & \\
\hline Petunidin-3-glucoside & & & & & & & & & & $\mathbf{X}$ & \\
\hline Phloretin & & & $\mathbf{X}$ & & & & & & & & \\
\hline Phloridzin & & & $\mathbf{X}$ & & & & & & & & \\
\hline trans-Piceid & & & & & & & $\mathbf{X}$ & & & & \\
\hline Protocatechuic acid & & & & & & & $\mathbf{X}$ & & & & \\
\hline Quercetin-3-O-glucoside & $\mathbf{X}$ & & & & & & $\mathbf{x}$ & & & & \\
\hline Quercetin-3-O-rhamnoside & & & & & $\mathbf{X}$ & & & & & $\mathbf{X}$ & \\
\hline Quercetin-3-O-rutinoside & & & & & & & $\mathbf{X}$ & & & & \\
\hline Synephrine & & & & $\mathbf{X}$ & & & & & & & \\
\hline Syringic acid & $\mathbf{X}$ & & & & & & & & & & \\
\hline Trigonelline & $\mathbf{X}$ & & & $\mathbf{X}$ & & & & $\mathbf{X}$ & & & $\mathbf{X}$ \\
\hline Vanillic acid & $\mathbf{x}$ & & & & & & $\mathbf{X}$ & & & & \\
\hline \multicolumn{12}{|l|}{ Fatty acids, lipids } \\
\hline Fatty acids & & & & & & & $\mathbf{X}$ & & & & \\
\hline$\alpha$-Linolenic A. & $\mathbf{X}$ & & & & & & & & & & \\
\hline \multicolumn{12}{|l|}{ Others } \\
\hline$\beta$-Carotene & & & & & & $\mathbf{X}$ & & & & & \\
\hline
\end{tabular}

a $[12] ;{ }^{\mathrm{b}}[13] ;{ }^{\mathrm{c}}[14,15] ;{ }^{\mathrm{d}}[16] ;{ }^{\mathrm{e}}[6,17] ;{ }^{\mathrm{f}}[18] ;{ }^{\mathrm{g}}[11,19,20] ;{ }^{\mathrm{h}}$ [21]; ${ }^{\mathrm{i}}$ [22]; ${ }^{\mathrm{j}}$ [23]; ${ }^{\mathrm{k}}$ [24]. Abbreviations: ATP, adenosine-triphosphate; GLUtCA, $\mathrm{O}^{3}-\beta$-D-glucopyranosyltrans-caffeic acid; GLUcCA, $\mathrm{O}^{3}$ - $\beta$-D-glucopyranosyl-cis-caffeic acid. 

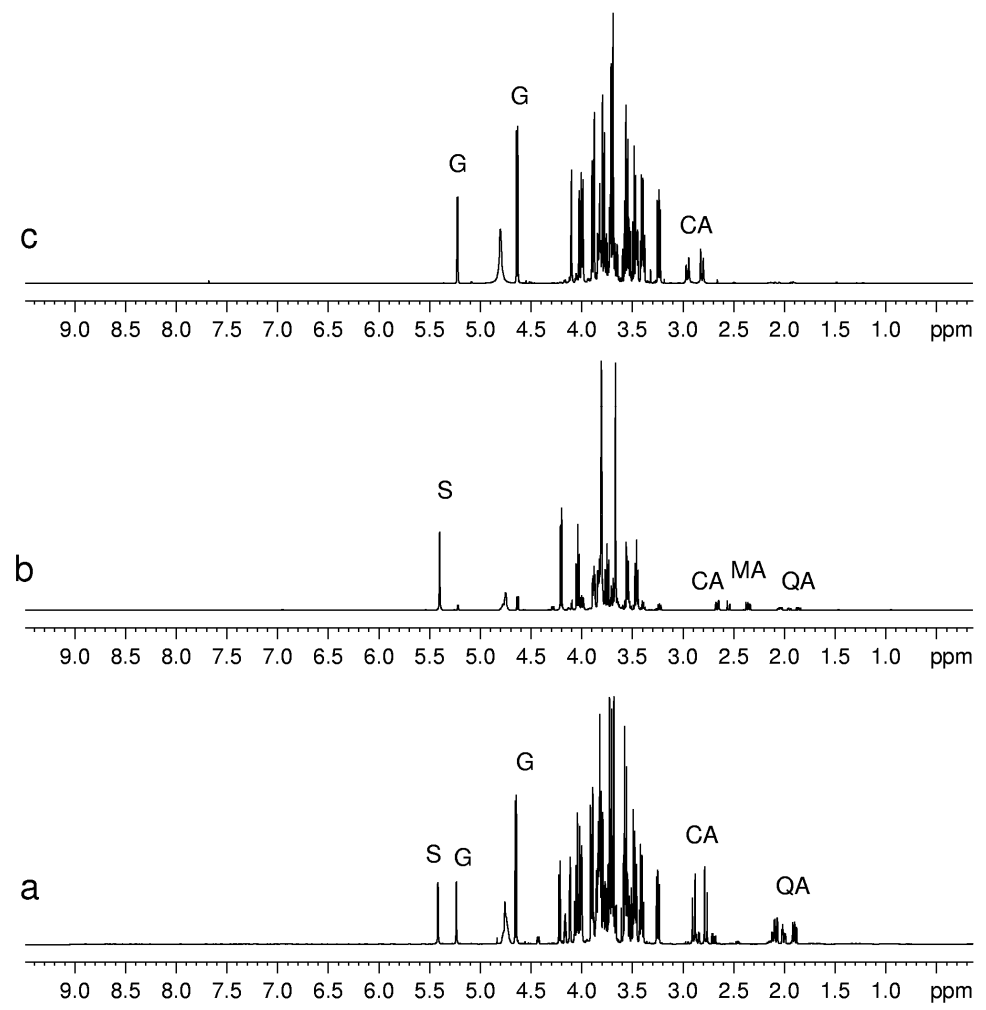

Figure 2. ${ }^{1} \mathrm{H}-\mathrm{NMR}$ spectra of aqueous extracts of (a) kiwifruits; (b) peach fruits; (c) blueberry fruits. Abbreviations: S, sucrose; G, glucose; CA, citric acid; MA, malic acid; QA, quinic acid.
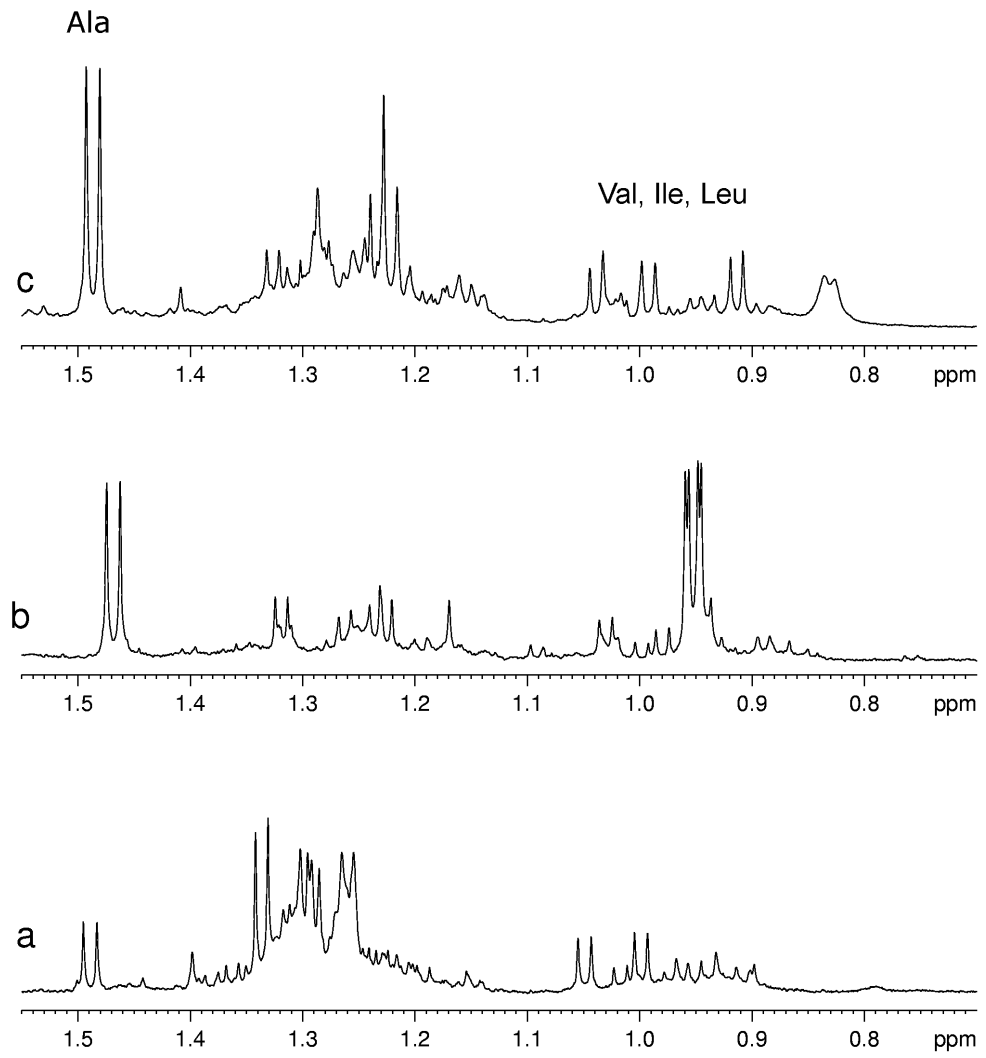

Figure 3. A selected region of ${ }^{1} \mathrm{H}-\mathrm{NMR}$ spectra of aqueous extracts of (a) kiwifruits; (b) peach fruits; (c) blueberry fruits. 
Sugars such as glucose, sucrose and fructose have been detected in all fruits, whereas others, present in minor concentration, have only been detected in some fruits. For instance, trehalose was detected only in mandarin orange [16] and melon fruits [21], whereas raffinose is seen only in kiwifruits [6]. Sugars can be identified easily by means of chemical shifts and coupling constants of their anomeric protons. Usually the signals of non-anomeric protons are not useful for identification, being overlapped in a narrow region between 3.2 and $4.0 \mathrm{ppm}$. However, in some specific cases, the non-anomeric proton signals are out of this range and therefore can be used for sugar identification. It is the case of the doublet at $1.28 \mathrm{ppm}$ ascribed to $\mathrm{CH}_{3}$ group of $\beta$-rhamnose detected in peach and mango. The detection of phosphorylated sugars (fructose and glucose) in peach and kiwifruits has been achieved by means of ${ }^{31} \mathrm{P}$ NMR experiments, see Figure 4.

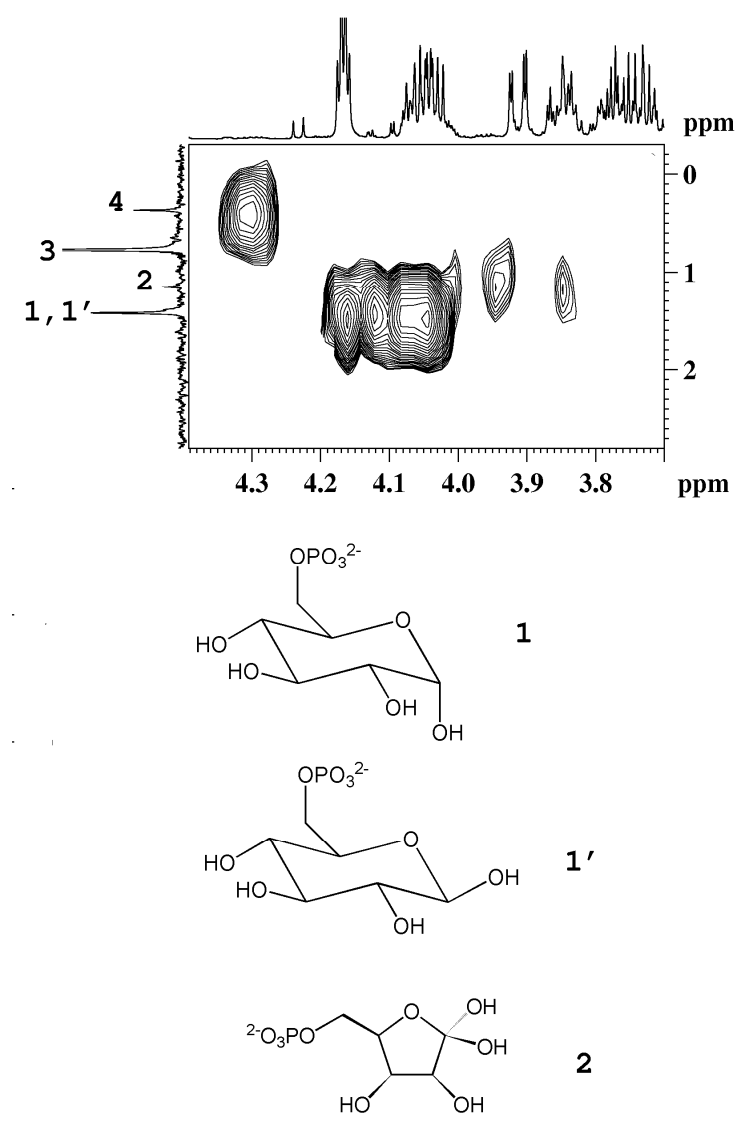

Figure 4. ${ }^{1} \mathrm{H}^{31} \mathrm{P}$ HMBC map of an aqueous extract of kiwifruit. The ${ }^{1} \mathrm{H}$ and the ${ }^{31} \mathrm{P}\left\{{ }^{1} \mathrm{H}\right\}$-decoupled NMR spectra are reported as projections in the $\mathrm{F} 2$ and $\mathrm{F} 1$ dimensions, respectively. 1, 1', $\alpha$-glucose-6-phosphate and $\beta$-glucose-6-phosphate; 2 , fructose-6-phosphate; 3 , orthophosphate; 4, unassigned compound (adapted from [6]).

Regarding amino acids, alanine and valine are almost ubiquitous, whereas glycine and methionine have been detected only in black raspberry and grape, respectively. Ornithine has been detected only in orange and mango, whereas lysine has been detected in kiwifruits and mango. Pyroglutamate has been observed only in melon.

Apart from ubiquitous metabolites, fruits contain specific secondary metabolites, usually present in minor concentrations compared with primary metabolites. These metabolites are often important from the nutraceutical point of view having antioxidant, anti-inflammatory and antimicrobial activities. 
Some of the secondary metabolites are characteristic for specific fruits and thus can be considered "markers" of the product.

For instance, NMR analysis has enabled the detection of phloretin and its glucoside conjugate phloridzin dihydrochalcones, specific antioxidants in apples [14]. Another secondary metabolite is narirutin, which is specific for Citrus genus fruits and has been identified in orange juice [13]. According to NMR analysis [16], mandarin orange fruits contain synephrine, a bioactive compound unique to Citrus [25] with vasoconstrictor and bronchiectatic properties [26] and effects on weight loss/weight management [27].

Some secondary metabolites are frequently observed in different fruits. For instance, trigonelline, an alkaloid with health-promoting properties (hypoglycaemic, hypocholesterolemic, antimigraine activities) [28] has been detected in NMR spectra of grapes, mandarin orange, melon, and peach.

The observation of secondary metabolites in the ${ }^{1} \mathrm{H}-\mathrm{NMR}$ spectra of crude extracts can be hindered by the presence of major components. In fact, the difference between the concentration of the major and minor components of a metabolite mixture can be beyond the limited dynamic range of a NMR spectrometer. In this case, the limit of detection for the minor component in the mixture is higher than the limit of detection for the same compound isolated from the mixture. Therefore, sometimes, in order to obtain more detailed information on specific minor compounds, a targeted NMR approach can be complementary to untargeted NMR as in the case of blueberries, where targeted NMR analysis focused on phenols and untargeted NMR metabolite profiling have been carried out [23]. Phenolic acids and anthocyanins have been isolated using solid phase extraction (SPE) with C18 column, afterwards the mixture of $\mathrm{CD}_{3} \mathrm{OD}$ and $\mathrm{CF}_{3} \mathrm{COOD}(95: 5 \mathrm{v} / \mathrm{v})$ has been used as a solvent to obtain high resolution NMR spectra. Five anthocyanins have been identified, namely, malvidin-3-glucoside, malvidin-3-galactoside, delphinidin-3-glucoside, delphinidin-3-galactoside, and petunidin-3-glucoside. Interestingly, only traces of cyanidin glycosides have been detected, despite the fact that usually cyanidins are the major components of anthocyanin fraction in blueberry. Besides anthocyanins, other phenolic compounds such as 3-O- $\alpha$-L-rhamnopyranosyl quercetin and chlorogenic acid have been identified by NMR.

\subsection{Quantitative Analysis and Statistical Elaboration}

The application of NMR in fruit metabolite study is not limited to qualitative analysis. NMR is also a robust quantitative technique provided that the following NMR experimental conditions are satisfied. The NMR signal area is proportional to the metabolite concentration provided that the complete relaxation of metabolite nuclei is achieved, therefore a recycle time (the time between successive spectral scans) of at least five times the longitudinal relaxation time $\left(\mathrm{T}_{1}\right)$ of the slowest relaxing nuclei is necessary after a $90^{\circ}$ pulse. The other important condition, a suitable signal-to-noise ratio, must be satisfied by choosing a proper number of scans. The NMR sensitivity is considered one of the main limitations in its application to metabolomic analysis. However, continuous developments in hardware as well as the invention and development of cryogenic probes [29] have allowed the sensitivity of NMR to be much increased.

The integration of a specific signal area $v s$. the signal area of reference compound can be used for absolute quantification yielding the amount of a specific metabolite in a given sample. Apart from the integration, other methods can be used to extract quantitative data from NMR spectra. 
An NMR spectrum itself represents a metabolic "fingerprint" of the sample under investigation and can be used as such, without identification of selected signals. Instead of using the integral of selected resonances, the whole spectrum can be divided into relatively narrow regions, typically $0.02-0.06 \mathrm{ppm}$ each one, and the total area within each region is calculated and considered in further analysis. This frequently used type of treatment, called bucketing or binning, has the advantage to overcome the problem of peak position and line width changes across the samples.

When a large amount of data is generated and the extraction of the desired information becomes complicated, chemometric methods are applied. Explorative unsupervised and supervised classification methods used in fruit NMR analysis are widely described in many papers and reviews [10,30,31].

The number of metabolites detectable simultaneously by NMR depends not only on the sensitivity and dynamic range but also on the selectivity of the extraction and on the number of extractions. In addition, some plant metabolites are bound in the cell, and are hard to extract. Therefore, the number of compounds actually present in a fruits extract after just one extraction is much smaller than the number of metabolites really present in the fruit. Only a small part of metabolome, "the tip of the iceberg", can be detected in a single NMR experiment even by employing high magnetic fields and cryoprobes. However, although the number of compounds detected in an extract is limited, the NMR spectra give a good picture of what actually occurs in the sample. Minor compounds might not be revealed, but the major trends are clear.

The quantitative elaboration of the metabolic profile along with statistical analysis can be effectively applied for assessing some important physiological and botanical aspects of fruits such as development and ripening, variety discrimination, quality control and geographical origin. Examples of these applications are given below.

\subsubsection{Development and Ripening}

NMR can be used to monitor the changes in metabolic profile of fruits during development and ripening and to provide objective criteria for determining the proper stage of fruit maturation. Moreover, it is possible to monitor metabolite composition of different fruit varieties useful to industrial applications.

Biochemical changes of black raspberry fruits at different stages of maturation (from unripe green to fully ripe dark red fruits) have been monitored by NMR coupled with multivariate statistical data analysis [19]. Two extraction solvents $\left(\mathrm{CH}_{3} \mathrm{OH} / \mathrm{H}_{2} \mathrm{O} 1: 1\right.$, or ethyl acetate) have been used and the metabolites extracted by $\mathrm{CH}_{3} \mathrm{OH} / \mathrm{H}_{2} \mathrm{O}$ were solubilized in $\mathrm{D}_{2} \mathrm{O}$ or in a mixture of $\mathrm{D}_{2} \mathrm{O}$ with $\mathrm{CD}_{3} \mathrm{OD}$ and trifluoroacetic acid. Using different NMR solvents for dissolution of the same extract, noticeably different NMR spectra were observed. In fact, although totally 36 metabolites were identified, only 18 of them were clearly observed in both solutions. Only two metabolites have been assigned in the ${ }^{1} \mathrm{H}$ spectra of ethyl acetate extracts leaving aside the assignment of the major part of the spectrum. Binning of selected regions in ${ }^{1} \mathrm{H}-\mathrm{NMR}$ spectra was applied for quantitative analysis and PCA and PLS-DA chemometric methods. According to NMR data, sucrose and most of the amino acids and organic acids decreased, whereas fructose, glucose, and cyanidins increased in relative concentration during maturation of black raspberry fruits. The levels of the metabolites identified in the ${ }^{1} \mathrm{H}-\mathrm{NMR}$ 
spectra show substantial changes during fruit ripening and the application of PLS-DA allowed the samples to be grouped according to the stage of ripeness.

The results reported by Gil et al. [18] described the use of high resolution magic angle spinning (HR-MAS) and liquid-state NMR spectroscopy to follow the ripening induced postharvest compositional changes in intact mango pulp and in mango juice, respectively. About 40 metabolites other than the main sugars have been identified in mango samples at different ripening stages. In pulp sucrose predominated over fructose and glucose at most ripening stages. The variation of each sugar with ripening in pulp has been in agreement with that reported previously for mango juice. On the other hand, in the juice the relative sugar composition and its variation with ripening differed significantly from that reported in literature. A possible explanation is that sucrose hydrolysis occurred to some extent before recording juice spectra. Citric acid has been the most abundant organic acid in unripe mango, however it decreased abruptly after the initial stages of ripening. During ripening a significant increase in alanine and a lesser increase in lactate, GABA, phenylalanine, and niacin, have been detected. It should be emphasized that amino acids, such as alanine, valine, leucine, isoleucine, phenylalanine and aspartic acid, are involved in aroma biosynthesis in fruits (2- and 3-methyl butanal, 2- and 3-methyl butanol, phenylacetaldehyde, 2-phenylethanol, methyl salicylate). Changes observed in the aromatic spectral region of the pulp indicate the complex chemistry of polymeric phenolic compounds and suggested the possible role of formic, gallic, and shikimic acids, and tyrosine as precursors in the polymerization processes.

The metabolite profiling of aqueous extracts of kiwifruit (Actinidia deliciosa (A.Chev.) C.F.Liang \& A.R.Ferguson, Hayward cultivar) grown in Italy has been monitored over the production season from June to December using ${ }^{1} \mathrm{H}$ high resolution NMR [6,17]. About 40 water-soluble metabolites have been assigned by means of 1D- and 2D-NMR experiments. The metabolite profiling has been used to investigate the kiwifruit development during the season. The analysis has shown that some metabolites were always present, although in different concentration, whereas other metabolites were present only in some months. The intensity of $29{ }^{1} \mathrm{H}$ resonances always present from June to December has been used in PLS analysis, see Figure 5A.

A

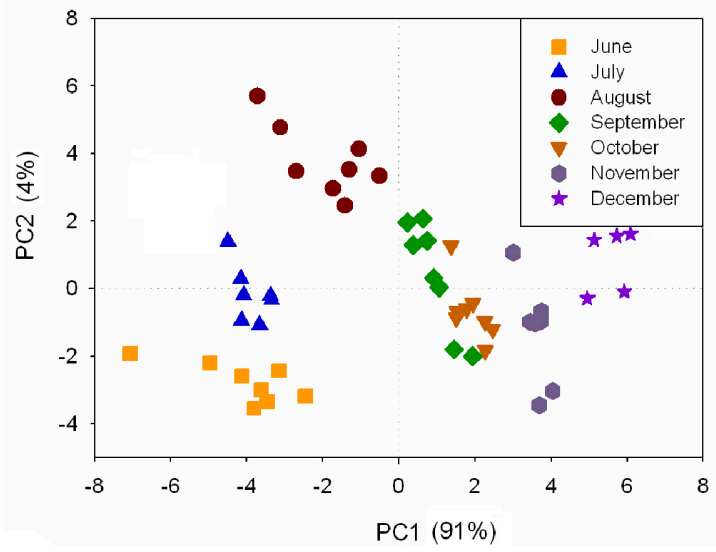

B

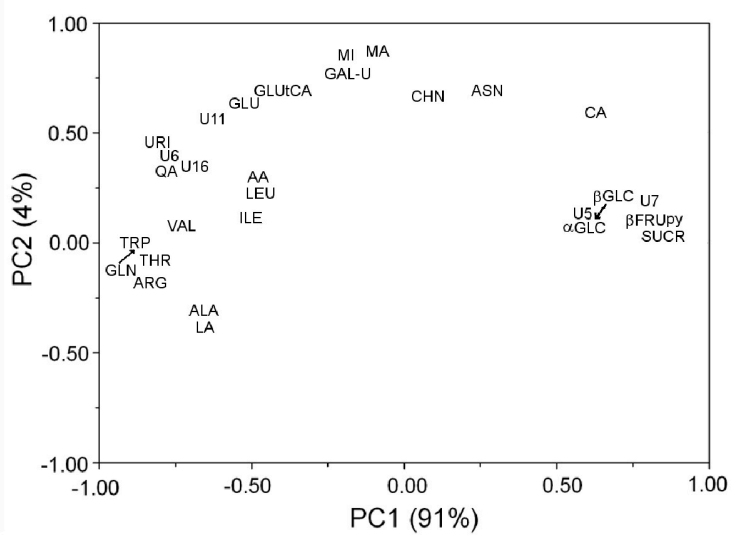

Figure 5. PLS analysis applied to the intensity of $29{ }^{1} \mathrm{H}$ resonances in kiwifruit aqueous extracts always present during the investigated period: (A) plot of PC sample scores and (B) plot of variable loadings (adapted from [6]). 
A clear grouping of kiwifruit samples according to the harvesting month is observable. Samples harvested in June, July, and August are grouped according to the specific campaign mainly along PC2. Samples collected later in the season are separated according to the specific campaign mainly along PC1. The effect of the growth is visible as a trend along PC1, in fact the centroid of each campaign group moves toward high PC1 values according to the kiwifruit growth. The contribution of the variables to this trend given by the variable loading shows that sucrose, fructopyranose, glucose, and citric acid were present in the highest concentration in the last months. Many amino acids such as valine, isoleucine, threonine, triptophane, leucine, alanine, arginine and glutamine, and some organic acids such as lactic acid, ascorbic acid, and quinic acid were present in the highest concentration in the first period.

The metabolites such as shikimic acid, $\mathrm{O}^{3}-\beta$-D-glucopyranosyl-trans-caffeic acid, $\mathrm{O}^{3}$ - $\beta$-Dglucopyranosyl-cis-caffeic acid, epicatechin, and 3-O- $\alpha$-L-rhamnopyranosyl quercetin present only in the first three months are intermediates of processes that can be observed only in this period. For example, shikimic acid, a biosynthetic precursor of phenylalanine, tyrosine, tryptophan, tannins, flavonoids and lignans, has been detectable only in June and July indicating its increased utilization over this time range in the production of some volatile compounds ( $p$-cresol, vanillin) and metabolites involved in the phenylpropanoids pathway, such as $\mathrm{O}^{3}-\beta$-D-glucopyranosyl-trans-caffeic acid. On the other hand, the observed increase in the $\mathrm{O}^{3}$ - $\beta$-D-glucopyranosyl-trans-caffeic acid level occurring in July and August might be associated also to the decrease in tryptophane level.

\subsubsection{Varieties Discrimination}

The metabolic profile of fruit varieties can give indications regarding sensorial properties and can be also useful to face some agronomic problems. For instance, in the case of peaches, fruit fly C. capitata attack results in a peach disease, causing economically important losses. One of the most promising approaches to limit the chance of attack is the development of varieties naturally resistant to insect attacks. Through the cross-breeding of varieties resistant to attacks with ones possessing good agronomic qualities, it might be possible to obtain a balance between those properties. Therefore, it is important to determine the molecules and molecular mechanisms involved in defence against insect attacks. In the paper by Capitani et al. [24], the metabolic profiling of peaches from two varieties, Flaminia (FP) and Percoca Romagnola 7 (PR7P), has been reported. FP, a Fayette-Fairtime cross-breeding variety is characterized by good sensorial properties and is used for fresh market but is easily attacked by $C$. capitata. On the other hand, PR7P, which is a clone identified within a Percoca population mainly commercialized in a local market and used also for the canning industry, is relevant in the selective breeding to increase the resistance to insect attacks. The NMR-based metabolic profiling has shown that the pulp of PR7P has contained greater amounts of alanine, quinic acid, chlorogenic and neochlorogenic acids than FP. These molecules have been reported to be related to the defence against fungal and insect attacks in other members of the Rosaceae family [32], suggesting that the phenylpropanoids pathway was at least partially involved in the repulsion of Ceratitis capitata. For instance, the metabolism of alanine and quinic acid leads to the biosynthesis of volatile compounds such as benzaldehyde and benzyl alcohol characterized by the ability to repel herbivore attacks [33]. At the same time, PR7P variety is poorer in valine and isoleucine [34] correlated with the formation of 
branched medium-length chain alcohols, acids, and aldehydes, which are volatiles known to attract the insect.

The investigation of metabolite composition of different fruit varieties can also give an important contribution to the development of data bases for the detection of adulterations and frauds of fruit juices. Many factors, such as geographical origin, storage, fruit varieties, and processing can potentially influence the metabolic profile of juices and must be taken into account. Preliminary studies on apple juices from different cultivars, years of production, and duration of storage have shown that the cultivar has been one of the most important sources of metabolite profile variability $[14,35,36]$. The levels of malic acid, phenolic compounds (epicatechin, phloridzin-phloretin, $p$-coumaric and chlorogenic acids) and sugars (glucose, fructose and sucrose) have been reported to be dependent on cultivar and hence mainly contributing in the differentiation of metabolite profiles of juices from different apple cultivars. According to a recent study [15], juices from the same cultivar but different geographical origin can have a different metabolite profile. ${ }^{1} \mathrm{H}-\mathrm{NMR}$ spectra of apple juices and pulp aqueous extracts from five different cultivars and two different regions (Japan and New Zealand) have been compared. Samples of Fuji cultivar from Japan contained larger amount of L-rhamnitol than New Zealand apples of the same cultivar. Moreover, sugars (sucrose, glucose, xylose), and acids (citramalic and quinic acids) have shown significant differences as well.

Another important aspect to take into account is the metabolic change during the process of juice production. Studies performed directly, without extraction, on fresh apple tissues using high resolution magic angle spinning (HR-MAS) ${ }^{1} \mathrm{H}-\mathrm{NMR}$ spectroscopy have shown distinct differences in some metabolites between apple tissue and juice [37]. For example, ethanol and acetaldehyde present in pulp were absent in juice, whereas lactic acid appeared in juice only. Apart from these differences between pulp and juice, the HR-MAS ${ }^{1} \mathrm{H}-\mathrm{NMR}$ study of metabolite profile of apple tissues derived from 3 different cultivars confirmed the influence of cultivar on the metabolite composition. The levels of malic acid, alanine, acetaldehyde, chlorogenic acid, epicatechin, sucrose and glucose were found to be different in the three cultivars.

Kiwifruits that include various Actinidia species have become an important horticultural crop for their sensory and nutritional properties. For many years only one fruiting cultivar, "Hayward", has dominated the international market. Recently, commercial cultivation of different Actinidia species with quite distinct fruits has begun to take hold. For example, a kiwifruit cultivar "CI.GI" crossbreed from different species of Actinidia deliciosa (A.Chev.) C.F.Liang \& A.R. Ferguson has been developed to obtain kiwifruits characterized by an earlier ripening than that of Hayward kiwifruits. In this way, it would be possible to have mature fruits even when Hayward kiwifruits are still unripe. Among other Actinidia species, Hort16A kiwifruit from Actinidia chinensis Planch, marketed under the name of Zespri Gold has assumed a certain commercial relevance being characterized by a yellow flesh and a flavor sweeter than that of Hayward kiwifruit. ${ }^{1} \mathrm{H}-\mathrm{NMR}$ has been applied to characterize the three kiwifruit cultivars mentioned above by assessing their metabolite profiles [17].

The metabolite profiling of Zespri, CI.GI, and Hayward kiwifruits displayed common metabolic features, such as high levels of quinic, citric, and ascorbic acid, but also important differences in the metabolic behavior during the growth and development of fruits [17]. For instance, the amount of $\mathrm{O}^{3}$ - $\beta$-D-glucopyranosyl-trans-caffeic acid was found to be higher in immature Hayward and CI.GI kiwifruits than in Zespri. Moreover, Hayward and CI.GI immature kiwifruits showed the presence of 
3-O- $\alpha$-L-rhamnopyranosyl quercetin that was absent in Zespri cultivar. Neochlorogenic acid found only in Zespri kiwifruits can be considered a specific marker of this variety. In Hayward and CI.GI kiwifruits a significant amount of epicatechin was detected in August, whereas in Zespri the amount of this compound was found to be low over the season.

NMR data for the metabolites common to all cultivars at each developmental stage have been subjected to PCA. Metabolic profiles of Zespri kiwifruits were always separated along the first principal component axis from the other two cultivars at each stage of development, whereas PCA analysis was not able to proof differences between Hayward and CI.GI kiwifruits over the season. To evidence a possible difference between these two cultivars, PLS2 analysis has been carried out using the same variables used for PCA. The most relevant metabolites responsible for this separation were found to be arginine, choline, myo-inositol, quinic acid, sucrose, uridine and histidine.

The combination of ${ }^{1} \mathrm{H}-\mathrm{NMR}$ and gas chromatography-electrospray ionization time-of-flight mass spectrometry (GC-EI-TOFMS) was used for metabolomic profiling of three cultivars (Cézanne, Escrito, and Hugo) of melon (Cucumis melo L.) fruit [21]. The metabolite composition of melon juice and fruit flesh extracts has been evaluated, 27 and about 40 metabolites were identified and quantified by NMR and GC-EI-TOFMS, respectively. PCA analysis applied to NMR data of fruit flesh extracts has revealed cultivar specific differences in metabolite content and has shown that the hexoses (e.g., glucose and fructose) with citric acid were more abundant in Cézanne cultivar, whereas almost all amino acids and sucrose had a higher level in Escrito cultivar. Glutamic acid has been the marker for the third cultivar, Hugo. Additionally, the spatial localization of the major polar metabolites in the different slices of melon flesh (epicarp, outer mesocarp and inner mesocarp) of the three cultivars has been assessed through ${ }^{1} \mathrm{H}-\mathrm{NMR}$ and GC-EI-TOFMS profiling. The cultivar-specific gradient of metabolite concentration from the epicarp to the inner mesocarp was observed for several metabolites, for example GABA gradient in Cézanne cv, acetic acid in Escrito cv, and malic and aspartic acids in Hugo cv. A multiblock hierarchical PCA method has been applied for correlation of data from ${ }^{1} \mathrm{H}-\mathrm{NMR}$ and GC-EI-TOFMS metabolomic platforms.

The sensory quality evaluation of seven cultivars of watermelon (Citrullus lanatus (Thunb.) Matsum. \& Nakai) grafted on two different rootstocks has been carried out and correlated with ${ }^{1} \mathrm{H}-\mathrm{NMR}$ metabolic profiles [22]. Twelve major metabolites have been assigned in the ${ }^{1} \mathrm{H}-\mathrm{NMR}$ spectra of juice extracted from the flesh tissues. Quantitative NMR data have been obtained using binning of entire spectrum except for water resonance, and PLS-DA have been employed as the supervised pattern-recognition method. The results have demonstrated that the quantity of sugar metabolites in the central flesh tissues was largely dependent on the rootstock cultivar, whereas, the watermelon cultivar had no significant effect on the sugar quantity and therefore on sensory properties of the flesh tissues from the central part of the watermelon. Based on the sensory evaluation, it could be inferred that sucrose was the predominant biochemical component contributing to the sweetness of watermelon.

\subsubsection{Quality Control}

Fruit juice profiling by ${ }^{1} \mathrm{H}-\mathrm{NMR}$ has been suggested as a method for authentication and verification in the quality control of fruit juices [38]. This approach has allowed the quantification of more than 
20 different compounds together with a fully automated screening using statistical models for the estimation of fruit content or the type and origin of the juice.

After having established a spectral database containing spectra of more than 3000 reference juices of about 1000 fully authentic samples in 2009, a constant update of the reference juice database is maintained. A specific case of adulteration, namely the addition of pulp wash to orange juice, has been evaluated using NMR metabolomics approach by Le Gall et al. [13]. Dimethylproline has been identified as a potential marker for the detection of pulp wash addition using PCA as unsupervised statistical analysis.

The detection of other frauds such as sugar addition, exhaustive enzymatic treatment, addition of citric acid or lemon juice, extraction of orange peel, or use of unripe fruits has been possible using fruit juice profiling by NMR [39]. Marker compounds like sucrose, galacturonic acid, and phlorin have been identified and quantified. To detect anomalies in the origin of a sample, the fruit content or the addition of other types of fruit, a non-targeted approach together with statistical methods has been applied. A large reference database has been developed with more than 6000 samples of more than 50 different types of fruit juices from more than 50 countries.

\subsubsection{Geographical Origin}

The effects of elevation, rootstock, and soil depth on the metabolic profile of mandarin orange juices prepared from fruits harvested in 11 different locations in California have been investigated by NMR [16]. About 30 metabolites have been identified, quantified and processed by multivariate statistical analysis.

In general, trees grown at a higher elevation tended to have higher concentrations of amino acids (specifically asparagine, threonine, phenylalanine, valine, alanine, and arginine), succinate, and 4-aminobutyrate but lower concentrations of sugars (glucose, fructose, sucrose), and limonin glucoside. Mandarin oranges taken from trees grown on trifoliate rootstock have the highest content of 4-aminobutyrate, ethanol, phenylalanine, isoleucine, and succinate. On a grove-to-grove basis, a 5-fold or even higher differences between the highest and the lowest concentrations of arginine, asparagine and proline have been observed. Some components, such as amino acids, limonin glucoside, 4-aminobutyrate, synephrine, trigonelline, and proline betaine, ranged from under $1 \mathrm{mM}$ to several millimolar. Sugars, acids, and aromatic compounds are considered the major components contributing to fruit quality and the fact that metabolite concentrations can vary so greatly depending upon the growth conditions of a grove suggests that fruits from each grove may have a particular taste profile.

\section{Acknowledgments}

This work has been carried out within the Ateneo2013 project "Alimenti di origine vegetale a elevato valore nutrizionale-funzionale: analisi del profilo metabolico e studio della digestione e degli effetti di trattamenti tecnologici di produzione sul contenuto di nutrienti e nutraceutici" using the facilities of MetabUnit-Rome. 


\section{Author Contributions}

L.M. and A.P.S. conceived, wrote and assembled the paper. M.D. and S.C. wrote the Introduction. D.C. wrote the section on Development and Ripening. R.A. performed the bibliographic research and wrote Geographical Origin. N.P. wrote Quality Control and A.M.G. wrote Varieties Discrimination. All authors read and approved the final manuscript

\section{Conflicts of Interest}

The authors declare no conflict of interest.

\section{References}

1. Nielsen, S.S. Food Analysis Laboratory Manual, 2nd ed.; Springer: New York, NY, USA, 2010; pp. 17-159.

2. Putri, S.P.; Nakayama, Y.; Matsuda, F.; Uchikata, T.; Kobayashi, S.; Matsubara, A.; Fukusaki, E. Current metabolomics: Practical applications. J. Biosci. Bioeng. 2013, 115, 579-589.

3. Cubero-Leon, E.; Peñalver, R.; Maquet, A. Review on metabolomics for food authentication. Food Res. Int. 2014, 60, 95-107.

4. Mannina, L.; Sobolev, A.P.; Viel, S. Liquid state ${ }^{1} \mathrm{H}$ high field NMR in food analysis. Prog. Nucl. Magn. Reson. Spectrosc. 2012, 66, 1-39.

5. Braun, S.; Kalinowski, H.O.; Berger, S. 2D NMR Spectroscopy with field gradients. In 150 and More Basic NMR Experiments, 2nd ed.; Wiley-VCH: Weinheim, Germany, 1998; pp. 476-528.

6. Capitani, D.; Mannina, L.; Proietti, N.; Sobolev, A.P.; Tomassini, A.; Miccheli, A.; Di Cocco, M.E.; Capuani, G.; de Salvador, R; Delfini, M. Monitoring of metabolic profiling and water status of Hayward kiwifruits by nuclear magnetic resonance. Talanta 2010, 82, 1826-1838.

7. Morris, K.F.; Johnson, C.S., Jr. Diffusion-ordered two-dimensional nuclear magnetic resonance spectroscopy. J. Am. Chem. Soc. 1992, 114, 3139-3141.

8. Gil, A.M.; Duarte, I.; Cabrita, E.; Goodfellow, B.J.; Spraul, M.; Kerssebaum, R. Exploratory applications of diffusion ordered spectroscopy to liquid foods: An aid towards spectral assignment. Anal. Chim. Acta 2004, 506, 215-223.

9. Novoa-Carballal, R.; Fernandez-Megia, E.; Jimenez, C.; Riguera, R. NMR methods for unravelling the spectra of complex mixtures. Nat. Prod. Rep. 2011, 28, 78-98.

10. McKenzie, J.S.; Donarski, J.A.; Wilson, J.C.; Charlton, A.J. Analysis of complex mixtures using high-resolution nuclear magnetic resonance spectroscopy and chemometrics. Prog. Nucl. Magn. Reson. Spectrosc. 2011, 59, 336-359.

11. Wizgoski, F.J.; Paudel, L.; Rinaldi, P.L.; Reese, R.N.; Ozgen, M.; Tulio, A.Z.; Miller, A.R.; Scheerens, J.C.; Hardy, J.K. Modeling relationships among active components in black raspberry (Rubus occidentalis L.) fruit extracts using high-resolution ${ }^{1} \mathrm{H}$ nuclear magnetic resonance (NMR) spectroscopy and multivariate statistical analysis. J. Agric. Food Chem. 2010, 58, 3407-3414.

12. Ali, K.; Maltese, F.; Fortes, A.M.; Pais, M.S.; Choi, Y.H.; Verpoorte, R. Monitoring biochemical changes during grape berry development in Portuguese cultivars by NMR spectroscopy. Food Chem. 2011, 124, 1760-1769. 
13. Le Gall, G.; Puaud, M.; Colquhoun, I.J. Discrimination between orange juice and pulp wash by ${ }^{1} \mathrm{H}$ nuclear magnetic resonance spectroscopy: Identification of marker compounds. J. Agric. Food Chem. 2001, 49, 580-588.

14. Belton, P.S.; Delgadillo, I.; Gil, A.M.; Roma, P.; Casuscelli, F.; Colquhoun, I.J.; Dennis, M.J.; Spraul, M. High-field proton NMR studies of apple juices. Magn. Reson. Chem. 1997, 35, S52-S60.

15. Tomita, S.; Nemoto, T.; Matsuo, Y.; Shoji, T.; Tanaka, F.; Nakagawa, H.; Ono, H.; Kikuchi, J.; Ohnishi-Kameyama, M.; Sekiyama, Y. A NMR-based, non-targeted multistep metabolic profiling revealed L-rhamnitol as a metabolite that characterised apples from different geographic origins. Food Chem. 2015, 174, 163-172.

16. Zhang, X.; Breksa, A.P., III; Mishchuk, D.O.; Slupsky, C.M. Elevation, rootstock, and soil depth affect the nutritional quality of mandarin oranges. J. Agric. Food Chem. 2011, 59, 2672-2679.

17. Capitani, D.; Mannina, L.; Proietti, N.; Sobolev, A.P.; Tomassini, A.; Miccheli, A.; Di Cocco, M.E.; Capuani, G.; de Salvador, F.R.; Delfini, M. Metabolic profiling and outer pericarp water state in Zespri, CI.GI and Hayward kiwifruits. J. Agric. Food Chem. 2013, 61, 1727-1740.

18. Gil, A.M.; Duarte, I.F.; Delgadillo, I.; Colquhoun, I.J.; Casuscelli, F.; Humpfer, E.; Spraul, M. Study of the compositional changes of mango during ripening by use of nuclear magnetic resonance spectroscopy. J. Agric. Food Chem. 2000, 48, 1524-1536.

19. Kim, H.-S.; Park, S.J.; Hyun, S.-H.; Yang, S.-O.; Lee, J.; Auh, J.-H.; Kim, J.-H.; Cho, S.-M.; Marriott, P.J.; Choi, H.-K. Biochemical monitoring of black raspberry (Rubus coreanus Miquel) fruits according to maturation stage by ${ }^{1} \mathrm{H}$ NMR using multiple solvent systems. Food Res. Int. 2011, 44, 1977-1987.

20. Paudel, L.; Wyzgoski, F.J.; Scheerens, J.C.; Chanon, A.M.; Reese, R.N.; Smiljanic, D.; Wesdemiotis, C.; Blakeslee, J.J.; Riedl, K.M.; Rinaldi, P.L. Nonanthocyanin secondary metabolites of black raspberry (Rubus occidentalis L.) fruits: Identification by HPLC-DAD, NMR, HPLC-ESI-MS, and ESI-MS/MS analyses. J. Agric. Food Chem. 2013, 61, 12032-12043.

21. Biais, B.; Allwood, J.W.; Deborde, C.; Xu, Y.; Maucourt, M.; Beauvoit, B.; Dunn, W.B.; Jacob, D.; Goodacre, R.; Rolin, D.; et al. ${ }^{1} \mathrm{H}$ NMR, GC-EI-TOFMS, and data set correlation for fruit metabolomics: Application to spatial metabolite analysis in melon. Anal. Chem. 2009, 81, 2884-2894.

22. Tarachiwin, L.; Masako, O.; Fukusaki, E. Quality evaluation and prediction of Citrullus lanatus by ${ }^{1} \mathrm{H}$ NMR-based metabolomics and multivariate analysis. J. Agric. Food Chem. 2008, 56, 5827-5835.

23. Capitani, D.; Sobolev, A.P.; Delfini, M.; Vista, S.; Antiochia, R.; Proietti, N.; Bubici, S.; Ferrante, G.; Carradori, S.; de Salvador, F.R.; et al. NMR methodologies in the analysis of blueberries. Electrophoresis 2014, 35, 1615-1626.

24. Capitani, D.; Sobolev, A.P.; Tomassini, A.; Sciubba, F.; de Salvador, F.R.; Mannina, L.; Delfini, M. Peach fruit: A metabolic comparative analysis of two varieties with different resistance to insect attacks by NMR spectroscopy. J. Agric. Food Chem. 2013, 61, 1718-1726.

25. Wheaton, T.; Stewart, I. Distribution of tyramine, $N$-methyltyramine hordenine, octopamine, and synephrine in higher plants. Lloydia 1970, 33, 244-254.

26. Takei, H.; Hirabuki, M.; Yoshizaki, F. Analysis of synephrine in the peel of citrus fruit, immature citrus fruit and decoctions of Chinese medicinal prescriptions containing these crude drugs by capillary electrophoresis. Anal. Sci. 1999, 15, 1017-1020. 
27. Stohs, S.J.; Preuss, H.G.; Shara, M. A review of the human clinical studies involving Citrus aurantium (bitter orange) extract and its primary protoalkaloid p-synephrine. Int. J. Med. Sci. 2012, 9, 527-538.

28. Adams, G.G.; Imran, S.; Wang, S.; Mohammad, A.; Kok, M.S.; Gray, D.A.; Channell, G.A.; Harding, S.E. The hypoglycemic effect of pumpkin seeds, Trigonelline (TRG), Nicotinic acid (NA), and D-Chiro-inositol (DCI) in controlling glycemic levels in diabetes mellitus. Crit. Rev. Food Sci. Nutr. 2014, 54, 1322-1329.

29. Styles, P.; Soffe, N.F.; Scott, C.A.; Crag, D.A.; Row, F.; White, D.J.; White, P.C.J. A high-resolution NMR probe in which the coil and preamplifier are cooled with liquid helium. J. Magn. Reson. 1984, 60, 397-404.

30. Izquierdo-García, J.L.; Villa, P.; Kyriazis, A.; del Puerto-Nevado, L.; Pérez-Rial, S.; Rodriguez, I.; Hernandez, N.; Ruiz-Cabello, J. Descriptive review of current NMR based metabolomic data analysis packages. Prog. Nucl. Magn. Reson. Spectrosc. 2011, 59, 263-270.

31. Ebbels, T.M.D.; Cavill, R. Bioinformatic methods in NMR-based metabolic profiling. Prog. Nucl. Magn. Reson. Spectrosc. 2009, 55, 361-374.

32. Michalek, S.; Klebel, C.; Treutter, D. Stimulation of phenylpropanoid biosynthesis in apple (Malus domestica Borkh.) by abiotic elicitors. Eur. J. Hortic. Sci. 2005, 70, 116-120.

33. Hernandez, M.M.; Vargas-Arispuro, I.; Sanz, I.; Adelantado, M.; Primo-Yufera, E. Electroantennogram activity and attraction assay of Ceratitis capitata to airborne volatiles from peach at three ripeness stages. Southwestern Entomol. 1999, 24, 133-142.

34. Light, D.M.; Jang, E.B.; Dickens, J.C. Electroantennogram responses of the Mediterranean fruit fly, Ceratitis capitata, to a spectrum of plant volatiles. J. Chem. Ecol. 1988, 14, 159-180.

35. Belton, P.S.; Colquhoun, I.J.; Kemsley, E.K.; Delgadillo, I.; Roma, P.; Dennis, M.J.; Sharman, M.; Holmes, E.; Nicholson, J.K.; Spraul, M. Application of chemometrics to the ${ }^{1} \mathrm{H}$ NMR spectra of apple juices: Discrimination between apple varieties. Food Chem. 1998, 61, 207-213.

36. Del Campo, G.; Santos, J.I.; Iturriza, N.; Berregi, I.; Munduate, A. Use of the ${ }^{1} \mathrm{H}$ nuclear magnetic resonance spectra signals from polyphenols and acids for chemometric characterization of cider apple juices. J. Agric. Food Chem. 2006, 54, 3095-3100.

37. Vermathen, M.; Marzorati, M.; Baumgartner, D.; Good, C.; Vermathen, P. Investigation of different apple cultivars by high resolution magic angle spinning NMR. A feasibility study. J. Agric. Food Chem. 2011, 59, 12784-12793.

38. Spraul, M.; Schütz, B.; Rinke, P.; Koswig, S.; Humpfer, E.; Schäfer, H.; Mörtter, M.; Fang, F.; Marx, U.C.; Minoja, A. NMR-based multi parametric quality control of fruit juices: SGF profiling. Nutrients 2009, 1, 148-155.

39. Spraul, M.; Schutz, B.; Humpfer, E.; Mortter, M.; Schafer, H.; Koswig, S.; Rinke, P. Mixture analysis by NMR as applied to fruit juice quality control. Magn. Reson. Chem. 2009, 47, S130-S137.

(C) 2015 by the authors; licensee MDPI, Basel, Switzerland. This article is an open access article distributed under the terms and conditions of the Creative Commons Attribution license (http://creativecommons.org/licenses/by/4.0/). 